\title{
An Analytical Solution to Simulate the Effect of Cement/Formation Stiffness on Well Integrity Evaluation in Carbon Sequestration Projects
}

\author{
Ben Li
}

\begin{abstract}
Cement Sheath integrity has been gain more attention due to the increase of carbon sequestration activities in the recent years. Sealing ability of cement sheath can be lost because mechanical disruption in the $\mathrm{CO}_{2}$ injection wells. Cement sheath mechanical failure can occur in the $\mathrm{CO}_{2}$ injection wells. This paper proposes an analytical solution to address this issue. Cement sheath and formation rock stiffness are considered in the proposed model to simulate the cement sheath sealing ability on different depth of the formation. Both mechanical properties of cement and formations are evaluated and analyzed. Real field example is also provided. Young's modulus of cement sheath is identified as a major factor that affects the sealing ability of cement sheath. The sealing ability of cement sheath in shale formation is better than that in sandstone formation. Weak cement has better sealing ability than strong cement. The critical failure point lies at the top of sandstone formation. This model can also be used to design and optimize the cement system of new $\mathrm{CO}_{2}$ injection wells in carbon sequestration projects.
\end{abstract}

Key Words: Stiffness Ratio; Cement Sheath; Well Integrity; Carbon Sequestration; Analytical Model

\section{Introduction}

Carbon sequestration is an effective way that has been used to mitigate severe climate change by injecting greenhouse gas such as carbon dioxide $\left(\mathrm{CO}_{2}\right)$ into depleted oil reservoirs. $\mathrm{CO}_{2}$ is injected into the void formations and the injected $\mathrm{CO}_{2}$ exists in supercritical condition. This is because the pressure and temperature of the storage formation are higher than the critical point of $\mathrm{CO}_{2}\left(7.38 \mathrm{MPa}\right.$ at $\left.31.1^{\circ} \mathrm{C}\right) . \mathrm{CO}_{2}$ is soluble in water, in which it reversibly forms carbonic acid $\left(\mathrm{H}_{2} \mathrm{CO}_{3}\right)$ and becomes corrosive. Even $\mathrm{H}_{2} \mathrm{CO}_{3}$ is a weak acid since its ionization in water is incomplete; cement sheath which was not corrosive resistant would be impaired and lost its sealing ability. This process is named as chemical degradation (Bruckdorfer, 1986). When a water injection well or oil production well is converted to $\mathrm{CO}_{2}$ injection well, the high injection pressure will result to the mechanical failure of the cement sheath (Takase et al., 2010). Cement sheath of a $\mathrm{CO}_{2}$ injection well is vulnerable due to the chemical degradation and mechanical disruption. The chemical degradation is mainly caused by carbonic acid when $\mathrm{CO}_{2}$ dissolves in brine water in the injected formations. Another reason is that most of the wells were initially cased and cemented without considering the $\mathrm{CO}_{2}$ corrosion effect. If the cement sheath of a well is lack of corrosive resistance ability, it is high possible that the well would lose its integrity during the life of carbon sequestration activity. The appearance of sustainable casing pressure is a major indicator of $\mathrm{CO}_{2}$ injection well leakage in carbon sequestration projects. 

scales (Bosma et al., 2009). The detrimental effects of cement sheath failure include lost revenue from lost production, potentially hazardous rig and producing operations (Deussen and Guyod, 1937). Laboratory investigations were conducted to simulate the conditions under which cement sheath failure could occur. Goodwin and Crook (1992) determined the effects of excessive pressure and temperature changes on cement sheath in casing/casing annuli by laboratory measurements. When test pressure reached or excessed the tensile strength of the cement sheath, the cracks radiated directly from the inner to the outer. Temperature changes can also create significant casing diameter changes. The axial stresses created by casing expansion cracked the cement sheath. The cracks opened sufficiently for the annular flow as the decreasing of the casing temperature. Boukhelifa et al. (2005) performed large scale laboratory tests on the cement sheath in an annular geometry. The influence of contraction and expansion of the inner casing were investigated. Failure modes of cement sheath were determined as a function of cement mechanical properties, loading parameters, and boundary conditions. $\mathrm{CO}_{2}$ corrosion effect on cement sheath integrity was also investigated. Kutchko et. al (2009) studied the effect of $\mathrm{CO}_{2}$ corrosion on Class H cement with Type F fly-ash as an additive. Tarco and Asghari (2010) investigated the effects of sulfate ions and $\mathrm{CO}_{2}$ on the macroscopic and microscopic properties and behavior of cement sheath using type 10 and Class $\mathrm{G}$ cement. The interaction between $\mathrm{CO}_{2-}$ rich brine and a single fracture within the cement sheath was published by Yalcinkaya et. al (2011).High-resolution X-ray computed tomography (CT) was used to identify the sub-volumes extracted from the flow-through cores. The corrosion effects of $\mathrm{CO}_{2}$ on geothermal cements with elevated temperatures $\left(>150^{\circ} \mathrm{C}\right)$ were studied by Milestone et. al (2012). $15 \%$ of silica flour can be used as a compromise between cement sheath compressive strength degradation and rate of carbonation/corrosion based on the results of this paper. Shadravan et al. (2015) proposed a laboratory method to investigate the effect of fatigue (cyclical loading) on the cement sheath. High pressure/ high temperature conditions were considered during the experimental investigation.

Analytical models and numerical models were also proposed to investigate cement sheath integrity. Thiercelin et al. (1998) presented a mechanical model to investigate the mechanical response of set cement in a cased wellbore. Bosma et al. (1999) used finite element analysis (FEA) models to study the influence of formation and loadings on the integrity of the cement sheath. Mueller et al. (2004) proposed an analytical model to predict the magnitude of tensile or compressive forces created by changing wellbore and reservoir conditions. Saint-Marc et al. (2008) presented a mechanics model considering initial state of stress. Teodoriu et al. (2010) developed an analytical model of wellbore stresses based on wellbore parameters. Thin and thick cylinder theories were used to estimate the well integrity under various downhole conditions. Haider et al. (2012) used a composite anxi-symmetric multi-cylinder wellbore model to study cement sheath integrity in carbon sequestration projects. Mohr-coulomb theory was used as cement sheath failure criteria. Shi et al. (2005) published an analytical solution to evaluate the 
stress state of casing-cement sheath-formation system. Initial loaded state and wellbore temperature variation were considered in their model.

However, all these models assumed isotropy formation stress exerted on the outer boundary of cement sheath. This paper proposes an analytical model with anisotropy formation stress and isotropy inner casing pressure. When a wellbore is cased and cemented, the stiffness of cement sheath and formation are also investigated by the implement of cement sheath/formation stiffness ratio. Cement sheath /formation stiffness ratio is used to describe the influence of formation stiffness on the sealing ability of cement sheath. Both shale and sandstone formation are investigated. The effect of cement sheath stiffness on the well integrity is also studied.

\section{Analytical Model}

An analytical solution is built to evaluate cement sheath integrity. The proposed model takes anisotropy formation stress into consideration. The interaction between cement sheath and formation are also addressed. The influence of different type of cement can be simulated in this solution. Both sandstone and shale formation can also be assessed. This section presents the derivation and construction of the analytical model.

\section{Anisotropy Formation Stress}

When a wellbore is cased and cemented, the cement sheath is assumed to be perfectly welded to the surrounding rock. All tractions and displacements will be continuous at the cement sheath/formation interface. The far-field principal stresses are $\sigma_{1}^{\infty}$ acting in the x direction and $\sigma_{2}^{\infty}$ in the y direction as shown in figure 1. Equation (1)-(3) describe the formation state of stress considering the influence of the cement sheath (Jaeger et al., 2007).

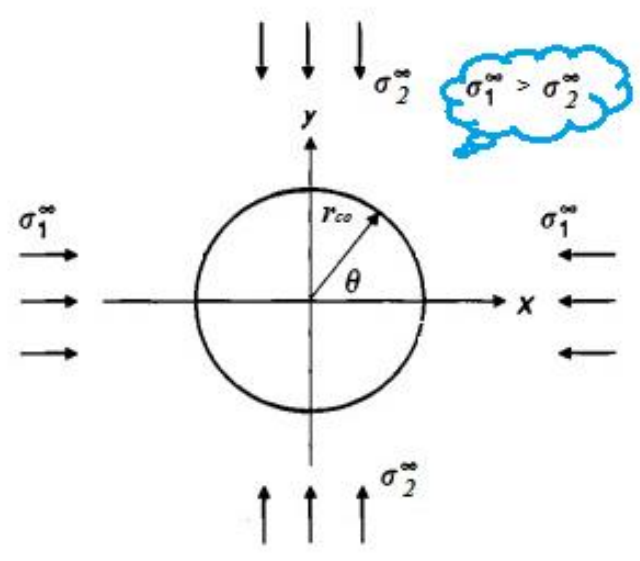

Figure 1 Full State of Stress around the Wellbore

$\sigma_{\theta f c}=\frac{1}{2}\left(\sigma_{1}^{\infty}+\sigma_{2}^{\infty}\right)\left[1+B\left(\frac{r_{c o}}{r}\right)^{2}\right]-\frac{1}{2}\left(\sigma_{1}^{\infty}-\sigma_{2}^{\infty}\right)\left[1-3 C\left(\frac{r_{c o}}{r}\right)^{4}\right] \cos 2 \theta$ 


$$
\begin{aligned}
& \sigma_{r f c}=\frac{1}{2}\left(\sigma_{1}^{\infty}+\sigma_{2}^{\infty}\right)\left[1-B\left(\frac{r_{c o}}{r}\right)^{2}\right]+\frac{1}{2}\left(\sigma_{1}^{\infty}-\sigma_{2}^{\infty}\right)\left[1-2 A\left(\frac{r_{c o}}{r}\right)^{2}-3 C\left(\frac{r_{c o}}{r}\right)^{4}\right] \cos 2 \theta \\
& \tau_{r \theta f c}=-\frac{1}{2}\left(\sigma_{1}^{\infty}-\sigma_{2}^{\infty}\right)\left[1+A\left(\frac{r_{c o}}{r}\right)^{2}+3 C\left(\frac{r_{c o}}{r}\right)^{4}\right] \sin 2 \theta
\end{aligned}
$$

Where,

$$
\begin{aligned}
& A=\frac{2\left(1-\beta_{c f}\right)}{\beta_{c f} k_{f}+1} \\
& B=\frac{\left(k_{c}-1\right)-\beta_{c f}\left(k_{f}-1\right)}{2 \beta+\left(k_{c}-1\right)} \\
& C=\frac{\left(\beta_{c f}-1\right)}{\beta_{c f} k_{f}+1} \\
& \beta_{c f}=\frac{E_{c}}{E_{f}} \\
& k_{c}=3-4 v_{c} \\
& k_{f}=3-4 v_{f}
\end{aligned}
$$

The stiffness ratio $\beta_{c f}$ is defined as the ratio of the Young's modulus of the cement sheath to the formation. The appearance of cement sheath/formation de-bonding is also related to stiffness ratios.

\section{Stress of Wellbore Syetem}

Casing and cement sheath are considered as a hollow circular cylinder system as shown in Figure 2. The compound wellbore system can be treated as a compound cylinder with different materials. On the outer side of the cement sheath, radial stress $\sigma_{r c o}$ is the same as the formation radial stress $\sigma_{r f i}$ of the inner hole. Modified lame solution, Equation (4) and (5), is used to solve the state of stress in the compound wellbore system. The radial displacement of casing and cement sheath can be determined by equation (6) and (7), respectively.

$$
\begin{array}{ll}
\sigma_{r w}=\frac{\left(r_{c o}^{2} \sigma_{r c o}-r_{s i}^{2} P_{i}\right)}{r_{c o}^{2}-r_{s i}^{2}}+\frac{r_{c o}^{2} r_{s i}^{2}\left(P_{i}-\sigma_{r c o}\right)}{\left(r_{c o}^{2}-r_{s i}^{2}\right) r^{2}} & r_{s i} \leq r \leq r_{c o} \\
\sigma_{\theta w}=\frac{\left(r_{c o}^{2} \sigma_{r c o}-r_{s i}^{2} P_{i}\right)}{r_{c o}^{2}-r_{s i}^{2}}-\frac{r_{c o}^{2} r_{s i}^{2}\left(P_{i}-\sigma_{r c o}\right)}{\left(r_{c o}^{2}-r_{s i}^{2}\right) r^{2}} \quad r_{s i} \leq r \leq r_{c o} \\
\mu_{r w c}=\frac{1}{E_{c}}\left(\left(1-2 v_{c}\right) \frac{\left(r_{c o}^{2} \sigma_{r c o}-r_{s i}^{2} P_{i}\right)}{2\left(r_{c o}^{2}-r_{s i}^{2}\right)}-\frac{r_{c o}^{2} r_{s i}^{2}\left(P_{i}-\sigma_{r c o}\right)}{\left(r_{c o}^{2}-r_{s i}^{2}\right) r^{2}}\right) & r_{c i} \leq r \leq r_{c o} \\
\mu_{r w s}=\frac{1}{E_{s}}\left(\left(1-2 v_{s}\right) \frac{\left(r_{c o}^{2} \sigma_{r c o}-r_{s i}^{2} P_{i}\right)}{2\left(r_{c o}^{2}-r_{s i}^{2}\right)}-\frac{r_{c o}^{2} r_{s i}^{2}\left(P_{i}-\sigma_{r c o}\right)}{\left(r_{c o}^{2}-r_{s i}^{2}\right) r^{2}}\right) & r_{s i} \leq r \leq r_{s o}
\end{array}
$$



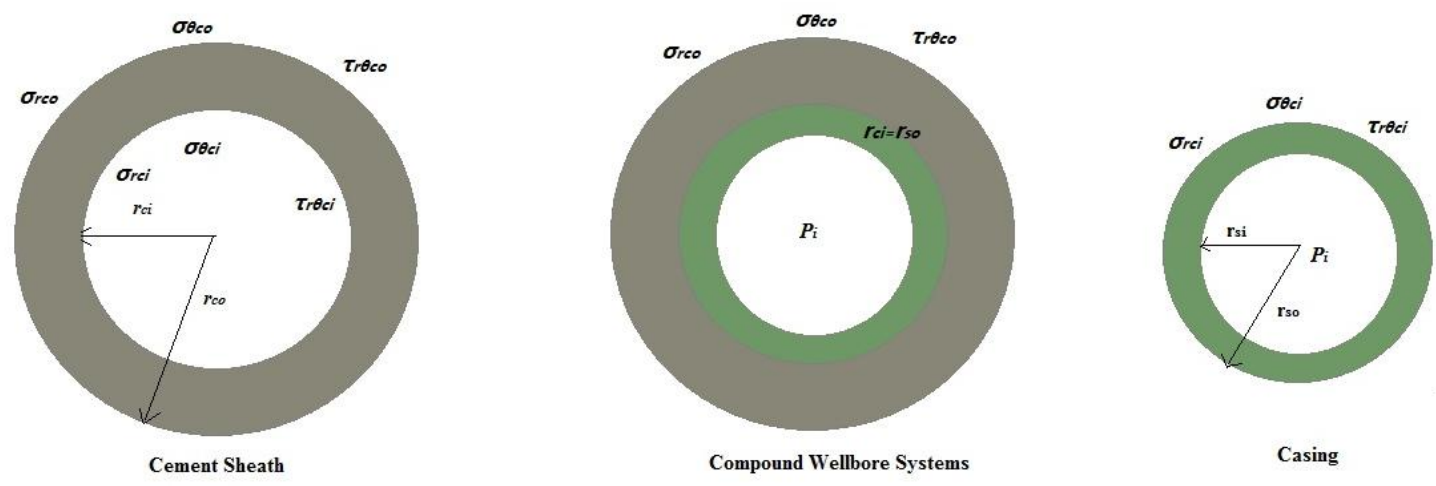

Figure 2 Compounds Wellbore System

The cased and cemented wellbore can be considered as compound cylinders, in which cement sheath are bonding on to the outside of casing. When cement sheath is set up between the casing and formation, bonding stresses $\sigma_{s c}$ and $\sigma_{c f}$ existed in the outer casing/inner cement sheath interface and in the outer cement sheath/inner wellbore formation interface, respectively as shown in figure 3 . The effects of bonding stress on cement sheath can be calculated by Equation (8) and (9).

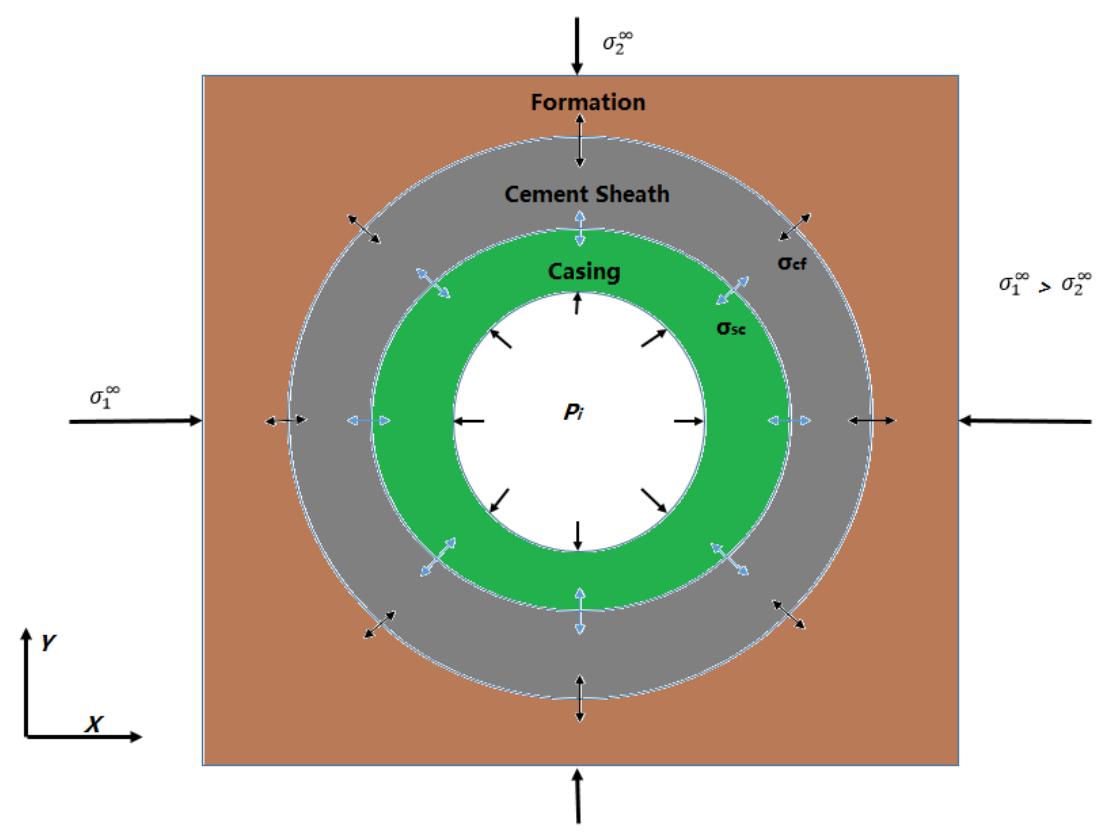

Figure 3 Stress State of Wellbore System

$$
\begin{array}{ll}
\sigma_{r c s}=\frac{\left(r_{c o}^{2} \sigma_{c f}-r_{c i}^{2} \sigma_{s c}\right)}{r_{c o}^{2}-r_{c i}^{2}}+\frac{r_{c o}^{2} r_{c i}^{2}\left(\sigma_{s c}-\sigma_{c f}\right)}{\left(r_{c o}^{2}-r_{c i}^{2}\right) r^{2}} & r_{c i} \leq r \leq r_{c o} \\
\sigma_{\theta c s}=\frac{\left(r_{c o}^{2} \sigma_{c f}-r_{c i}^{2} \sigma_{s c}\right)}{r_{c o}^{2}-r_{c i}^{2}}-\frac{r_{c o}^{2} r_{c i}^{2}\left(\sigma_{s c}-\sigma_{c f}\right)}{\left(r_{c o}^{2}-r_{c i}^{2}\right) r^{2}} & r_{c i} \leq r \leq r_{c o}
\end{array}
$$


The loads of cement sheath are external radial stress of formation at outer cement sheath/formation interface $\sigma_{r c o}$, external radial stress at outer casing/inner cement sheath interface generated by the inner casing pressure, initial state of stress induced by the cement sheath itself. Based on the principle of superposition, $\sigma_{r}$ and $\sigma_{\theta}$ can be calculated by the sum of stress generated by $P_{i}, \sigma_{r c o}, \sigma_{s c}, \sigma_{c f}$ as shown in equation (4), equation (5), equation (8)and equation (9). The cement sheath state of stress can be expressed by equation (10) and (11).

$\sigma_{r}=\sigma_{r w}+\sigma_{r c s}=\frac{\left(r_{c o}^{2} \sigma_{r c o}-r_{s i}^{2} P_{i}\right)}{r_{c o}^{2}-r_{s i}^{2}}+\frac{r_{c o}^{2} r_{i s}^{2}\left(P_{i}-\sigma_{r c o}\right)}{\left(r_{c o}^{2}-r_{s i}^{2}\right) r^{2}}+\frac{\left(r_{c o}^{2} \sigma_{c f}-r_{c i}^{2} \sigma_{s c}\right)}{r_{c o}^{2}-r_{c i}^{2}}+\frac{r_{c o}^{2} r_{c i}^{2}\left(\sigma_{s c}-\sigma_{c f}\right)}{\left(r_{c o}^{2}-r_{c i}^{2}\right) r^{2}}$

$\sigma_{\theta}=\sigma_{\theta w}+\sigma_{\theta c s}=\frac{\left(r_{c o}^{2} \sigma_{r c o}-r_{s i}^{2} P_{i}\right)}{r_{c o}^{2}-r_{s i}^{2}}-\frac{r_{c o}^{2} r_{s i}^{2}\left(P_{i}-\sigma_{r c o}\right)}{\left(r_{c o}^{2}-r_{s i}^{2}\right) r^{2}}+\frac{\left(r_{c o}^{2} \sigma_{c f}-r_{c i}^{2} \sigma_{s c}\right)}{r_{c o}^{2}-r_{c i}^{2}}-\frac{r_{c o}^{2} r_{c i}^{2}\left(\sigma_{s c}-\sigma_{c f}\right)}{\left(r_{c o}^{2}-r_{c i}^{2}\right) r^{2}}$

where $r_{c i} \leq r \leq r_{c o}$

\section{Failure Criteria}

Both tensile failure and shear failure criteria are used to evaluate the maximum allowable $\mathrm{CO}_{2}$ injection pressure $P_{\text {imax }}$. For the tensile failure, tangential stress of the cement sheath $\sigma_{\theta}$ as expressed in equation (11) must be lower than the tensile strength of the cement sheath.

$-\sigma_{\theta}<\sigma_{\text {tensile }}$

Failure index (FI) is used to assess the performance of cement sheath. The FI of tensile failure criteria is defined as shown in equation (13).

$F I_{\text {tensile }}=\frac{-\sigma_{\theta}}{\sigma_{\text {tensile }}}$

If $F I_{\text {tensile }}$ is greater than 1, tensile failure should happen in that position of the cement sheath. The cement sheath is free of tensile failure if $F I_{\text {tensile }}$ is less than 1 at any point of cement sheath.

The shear failure criteria used in this paper is Mohr-Coulomb theory as shown in equation (14). $\sigma_{\text {cohesion }}$ is cohesion of cement sheath, $\mathrm{psi} ; \varphi$ is internal friction angle of the cement sheath, degree.

$\left|\sigma_{r}\right| \leq \frac{2 \sigma_{\text {cohesion } \cos \varphi}}{1-\sin \varphi}+\left|\sigma_{\theta}\right| \frac{1+\sin \varphi}{1-\sin \varphi}$

The FI of shear failure criteria is defined as shown in equation (15).

$F I_{\text {shear }}=\frac{\left|\sigma_{r}\right|}{\left(\frac{2 \sigma_{\text {cohesion }} \cos \varphi}{1-\sin \varphi}+\left|\sigma_{\theta}\right| \frac{1+\sin \varphi}{1-\sin \varphi}\right)}$

If $F I_{\text {Shear }}$ is greater than 1, shear failure would happen in position of the cement sheath that. The cement sheath is free of shear failure if $F I_{\text {Shear }}$ is less than 1 at any point of cement sheath.

The proposed analytical solution was coded in MATLAB. The radial stress, tangential stress, FI of shear failure and tensile failure are presented in Figure 4, which provides visible image for the 
stress distribution and risky failure area. In figure 4, radical stress and tangent stress can be visually seen and stress concentration areas can be easily identified. Tensile failure and shear failure index as expressed in equation (13) and equation (15) are also coded as shown in Figure 4. With the visual display, it is relative easy to figure out the critical failure point of the cement sheath.
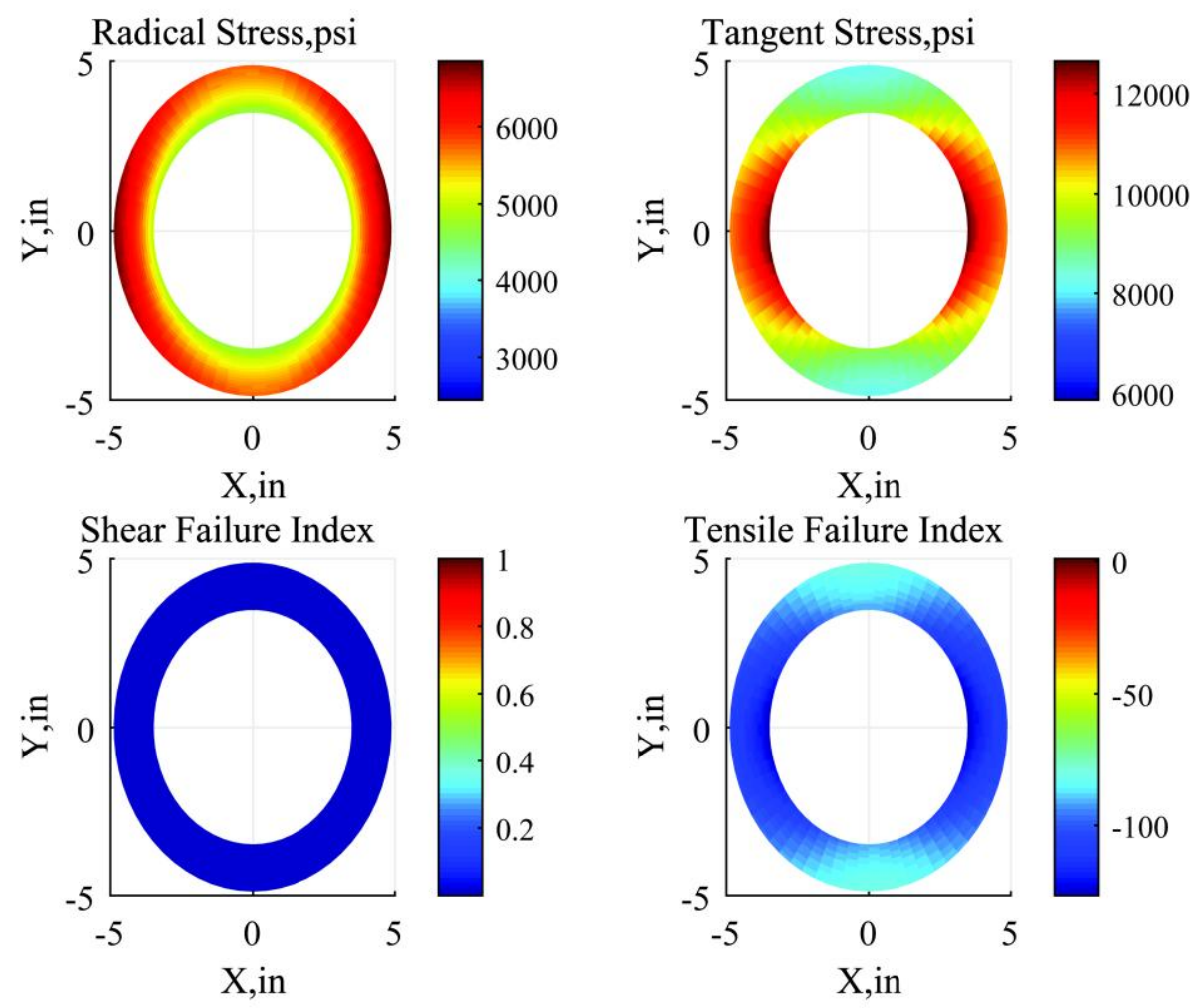

Figure 4 State of Stress and FI of Cement Sheath

\section{Analysis with Field Data}

WH field started $\mathrm{CO}_{2}$-EOR process in December 2010. $\mathrm{CO}_{2}$ is injected into Frio sandstone formation at 5,700ft with average pay zone thickness $100 \mathrm{ft}$. The average porosity is $30 \%$, and average horizontal permeability is $900 \mathrm{md}$. The gravity of the oil is $31^{\circ}$. Figure 5 is the $\mathrm{CO}_{2}$ injection area of WH field. 


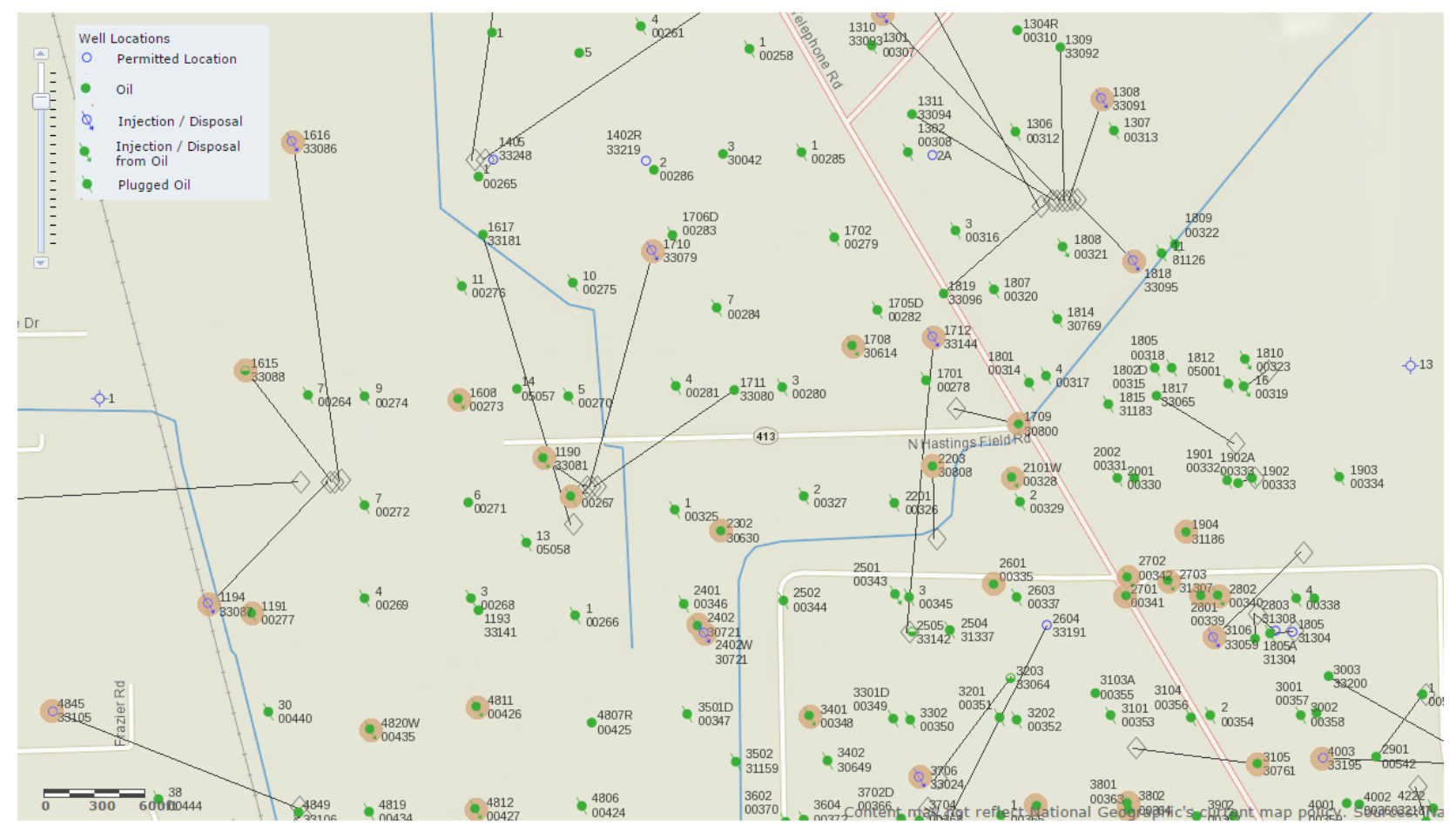

Figure $5 \mathrm{CO}_{2}$ Injection Area of $\mathrm{WH}$ Field

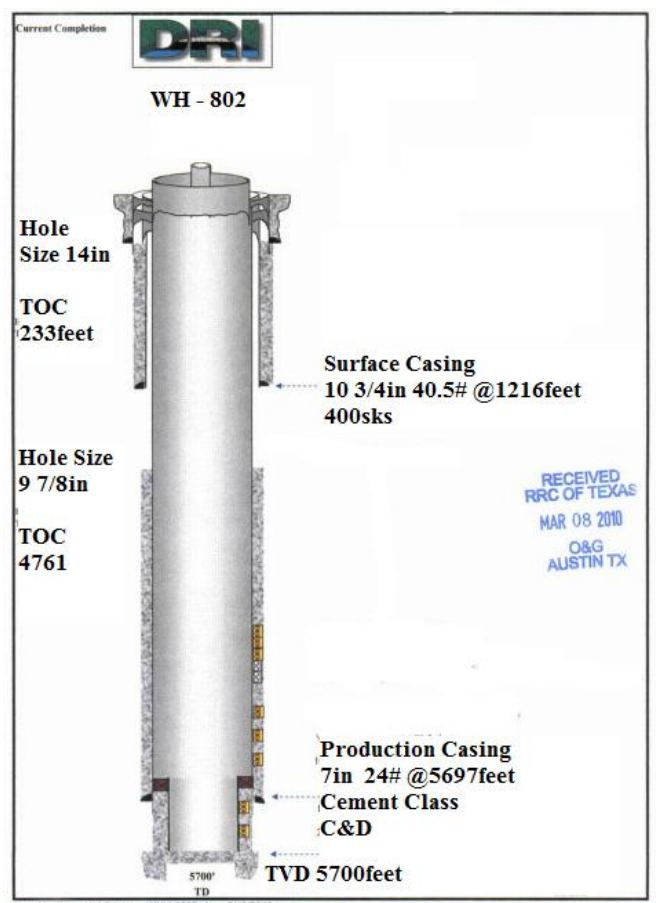

Figure 6 Construction Details of Well WH-802

Figure 6 is the construction details of Well WH-802. Table 1 presents the cementing data for a $\mathrm{CO}_{2}$ injection well (WH-802) in $\mathrm{WH}$ field. The $\mathrm{CO}_{2}$ injection zone of $\mathrm{WH} 802$ is from $5357 \mathrm{ft}$ to 
$6600 \mathrm{ft}$. Figure 6 shows the structure of WH-802. The packer depth is $5257 \mathrm{ft}$ and the inject tubing depth is $5307 \mathrm{ft}$. Table 2 presents properties of cement sheath and formation (Kalil and McSpadden, 2012). The mechanical properties of cement sheath and formation are unclear. Both weak cement and strong cement are considered in this study. Shale and sandstone formation are also addressed in the evaluation of cement sheath integrity. Parameters required for tensile failure and shear failure evaluation are also included in Table 2.

Table 1 Casing and Cement Data of Well WH-802

\begin{tabular}{lccc}
\hline Type of casing & $\begin{array}{c}\text { Surface } \\
\text { Casing }\end{array}$ & $\begin{array}{c}\text { Production } \\
\text { Casing }\end{array}$ & Liner \\
\hline Hole Size (in.) & 14 & 9.875 & 9.875 \\
Casing Depth (ft) & 1216 & 5,697 & 5,700 \\
Casing OD (in.) & 10.75 & 7 & 5 \\
Casing ID (in.) & 10.5 & 6.366 & 4.276 \\
Casing Weight (lb/ft) & 40.5 & 24 & 18 \\
Cement Used (sacks) & 400 & 300 & N/A \\
Top of Cement (ft) & 233 & 4751 & 5,916 \\
\hline
\end{tabular}

Table 2 Mechanical Properties of Cement Sheath and Formation Rock

\begin{tabular}{lccccc}
\hline \multicolumn{1}{c}{ Type } & $\begin{array}{c}\text { Young's } \\
\text { Modulus } \\
10^{6} \mathrm{Psi}\end{array}$ & $\begin{array}{l}\text { Poisson's } \\
\text { Ratio }\end{array}$ & $\begin{array}{c}\text { Tensile } \\
\text { Strength } \\
\text { Psi }\end{array}$ & $\begin{array}{l}\text { Friction } \\
\text { Angle } \\
\text { Degree }\end{array}$ & Cohesion \\
Weak Cement & 0.5 & 0.2 & 100 & 5 & 225 \\
Strong Cement & 1.5 & 0.15 & 100 & 40 & 500 \\
Sandstone & 1.03 & 0.32 & N/A & N/A & N/A \\
Shale & 0.23 & 0.43 & N/A & N/A & N/A \\
\hline
\end{tabular}

Cement sheath will fractured and lose its integrity when the $\mathrm{CO}_{2}$ injection pressure rises to a critical value. The pressure at the critical point is named as maximum allowable injection pressure (MAIP). In order to determine which failure would occur first, the basic assumption is that cement sheath is other failure free. For example, MAIP of tensile failure is calculated without considering shear failure of the cement sheath. MAIP of shear failure can also be determined at tensile failure free condition. When MAIP for both failure criteria are calculated, failure sequence can be identified by the failure with lower MAIP. Table 3 shows a summary of the MAIP of different failure criteria. 
Table 3 MAIP of Different Failure Criteria

\begin{tabular}{|c|c|c|c|c|}
\hline \multirow{3}{*}{ Cement Type } & \multicolumn{2}{|c|}{ Sandstone } & \multicolumn{2}{|c|}{ Shale } \\
\hline & Tensile & Shear & Tensile & Shear \\
\hline & Psi & Psi & Psi & Psi \\
\hline Weak Cemen & 3377 & 3328 & 6337 & 6289 \\
\hline Strong Cement & 4513 & 3158 & 7068 & 5085 \\
\hline
\end{tabular}

This analytical model addresses the effect of anisotropy stress effects. Shear failure happens when the difference between the two principle stress reach to a threshold value. This is mainly determined by the anisotropy degree of formation in-situ stress. While tensile failure is mainly caused by the increase of tangent stress. Both sandstone and shale formations have the same failure sequence as shown in Table 3. Tensile failure and shear failure would happen at almost the same time for the weak cement. For the strong cement, shear failure will appear earlier than tensile failure. In is situation, shear failure can be used as the primary failure criteria to evaluate the cement sheath integrity of WH 802.

\section{Effect of Young's Modulus}

Sensitive analysis is performed to evaluate the effect of Young's Modulus of cement sheath on MAIP. Internal friction angle and cohesive strength of both strong cement and weak cement are used to assess the shear failure of cement sheath. Figure 7 show that the Young's modulus has positive impact on the MAIP. The greater the Young's modulus of cement sheath, the well is more reliable. Wellbore cement with higher Young's modulus is preferred for the new well construction and design.

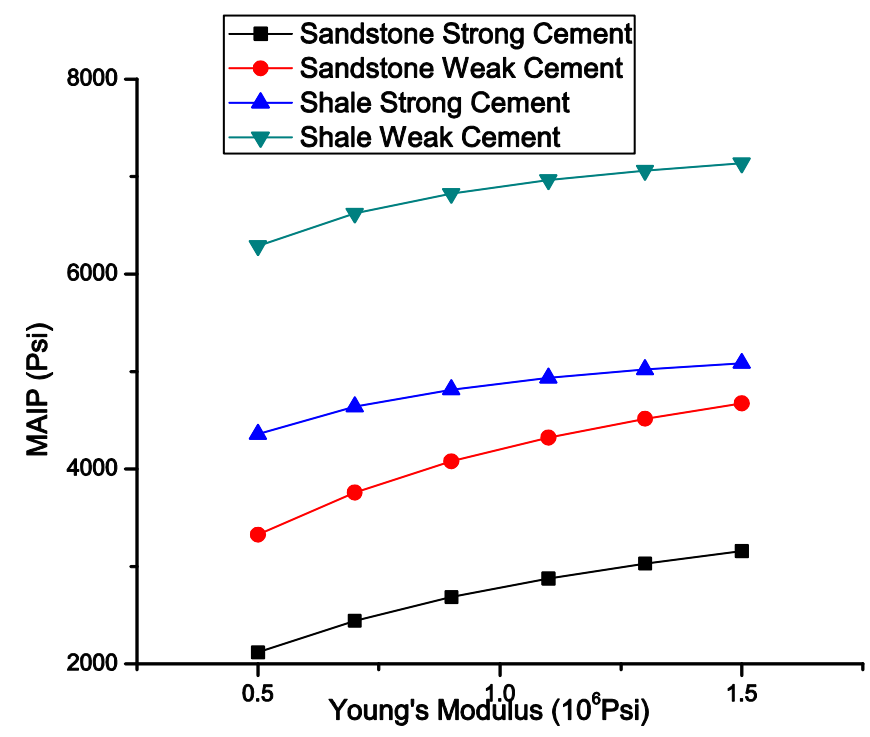

Figure 7 Effects of Young's Modulus on MAIP 


\section{Effect of Poisson's Ratio}

Poisson's ratio of cement sheath is ranged from 0.15 to 0.2 based on table 2. Figure 8 shows the effect of Poisson's ratio on MAIP. MAIP will slightly increase as the increase of Poisson's ratio for both strong cement and weak cement. Poisson's ratio has minor positive impact on MAIP.

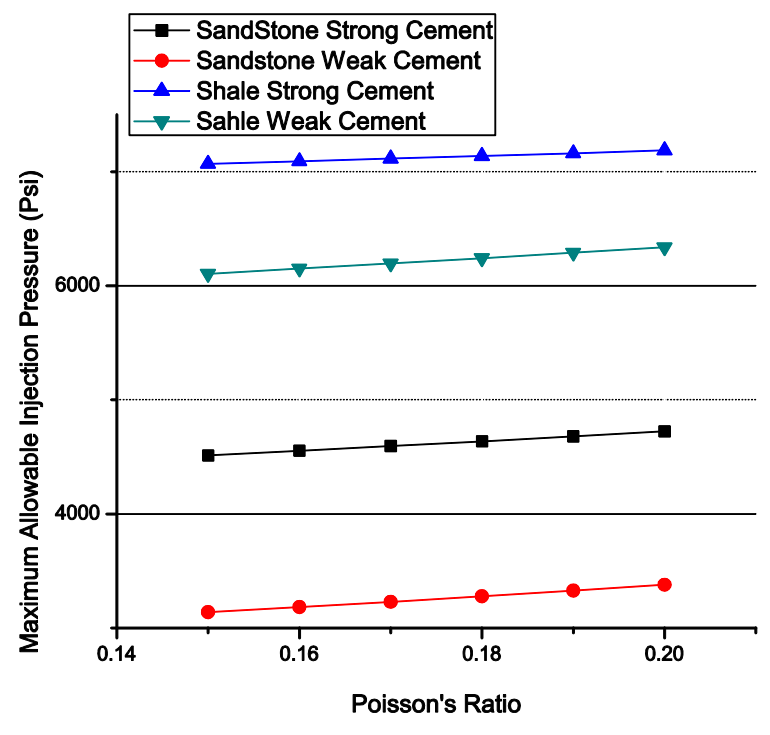

Figure 8 Effects of Poisson's Ratio on MAIP

\section{Effect of Cohesion}

Cohesion is defined as the cohesive force that takes place between adjacent particles. Cohesion of cement sheath is an important factor of Mohr-Coulomb theory. The cohesion of cement is caused by the composition of cement sheath such as $\mathrm{Fe}_{2} \mathrm{O}_{3}, \mathrm{CaCO}_{3}, \mathrm{Ca}(\mathrm{OH})_{2}$, etc. Figure 9 presents the effect of cement cohesion on MAIP. MAIP displays slight positive trend with cement cohesion.

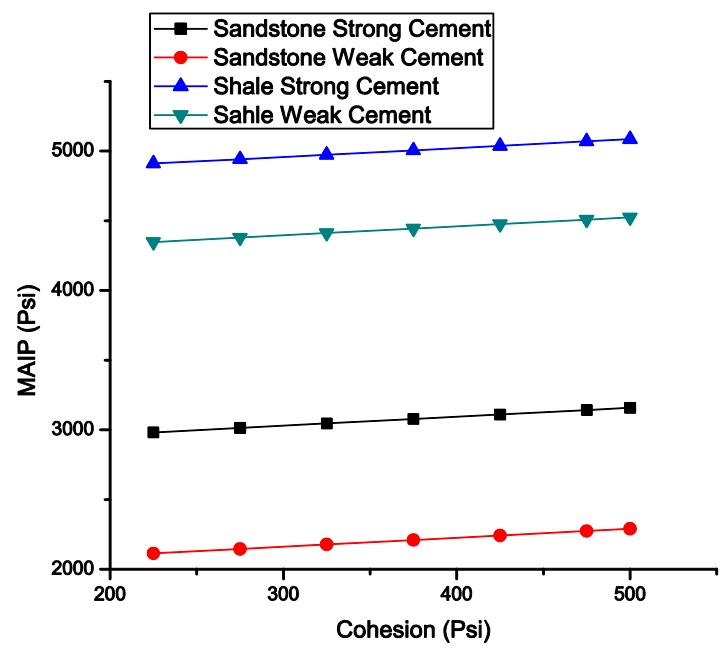

Figure 9 Effects of Cement Cohesion on MAIP 


\section{Effect of Formation Type}

Mechanic properties of cement sheath (Young's Modulus, Poisson's Ratio, and Cohesion) can affect the MAIP based on the analysis previously. This section analyses the effect of formation type on the MAIP. Equations (1) to (3) take the interaction between cement sheath and formation into account. The formation mechanic properties can also affect the MAIP. Figures 7 to 9 shows that the MAIP in the shale formation is higher than that of sandstone at the same depth. Cement with higher young's modulus, higher Poisson's ratio and higher cohesion are suggested to be used in the new $\mathrm{CO}_{2}$ injection well construction.

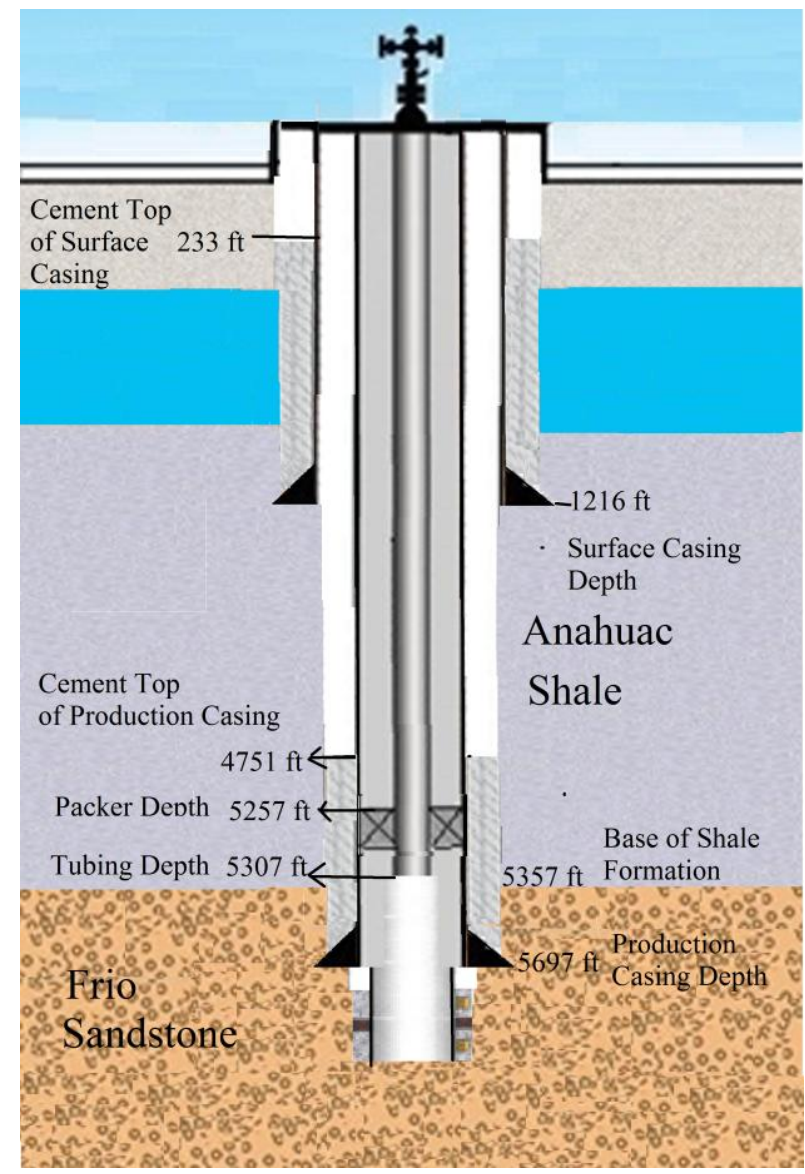

Figure 10 Formation Type along the Wellbore of WH802

It is impractical to measure the cement sheath at downhole conditions. Some experiments were conducted to investigate the mechanical properties of cement sheath by simulating the environment of downhole conditions. Some typical values were gained as shown in table 2 . Since the uncertainty of the mechanic properties of cement sheath, it is better to get a conservative value of MAIP when evaluate the cement sheath integrity. The sensitivity analysis performed previously can be used as a guide line to get the conserve value of MAIP. However, not all the cement sheath is in the conservative conditions, it can be better in resisting much higher tubing injection pressure. In order to take this situation into account, both weak cement 
and strong cement are evaluated. The mechanical properties are taken from table 2 . It is critical to evaluate the cement sheath integrity from the depth of packer to the production casing shoe. This interval can be ranged from shale formation to sandstone formation. The mechanical properties of sandstone and shale are shown in table 2.

WH Field is on a domal uplift having a structural pattern similar to many deep-seated salt domes in the Gulf Coast. It is in the prolific, Frio "fairway". There is approximately $600 \mathrm{ft}$ of Anahuac Shale with the Frio underlying the Anahuac (Thomas, 1953). The sealing performance of cement sheath is evaluated through the wellbore. The cement sheath integrity must be guaranteed from surface to bottom along the wellbore. Both Anahuac shale formation and Frio sandstone formation are evaluated along Well WH802. Figure 10 presents the formation type along the wellbore of WH 802. The evaluation interval can be from $5257 \mathrm{ft}$ to $5697 \mathrm{ft}$. The shale formation is from $5257 \mathrm{ft}$ to $5357 \mathrm{ft}$ while the sandstone formation is from $5357 \mathrm{ft}$ to $5697 \mathrm{ft}$.

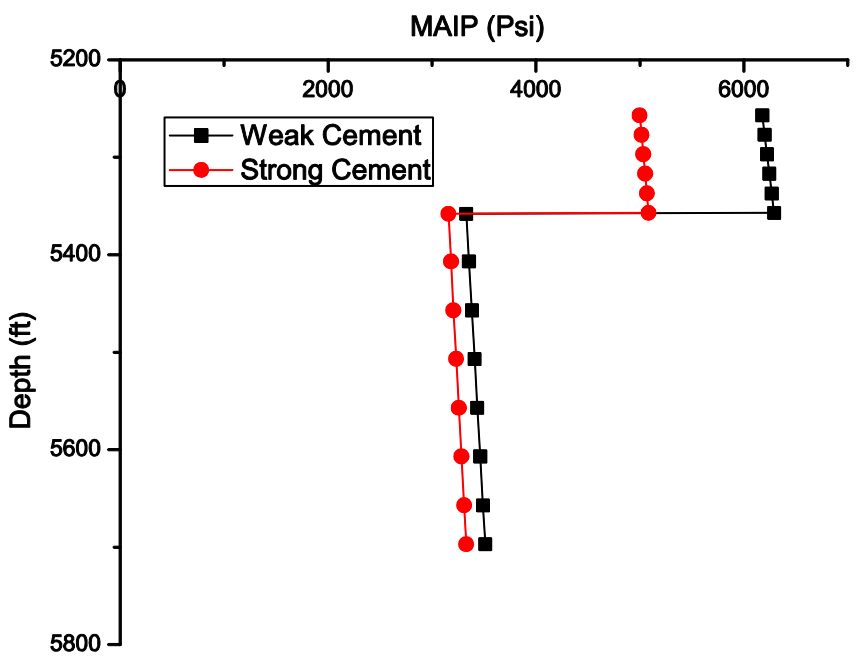

Figure 11 MAIP along the Wellbore of WH 802

Figure 11 presents the MAIP from packer depth to production casing shoe depth. Both weak cement and strong cement are evaluated from shale to sandstone formation. Conservative estimation is provided is given if mechanical properties of strong cement are used, while optimistic estimation is provided when mechanical properties of weak cement are used. In the shale formation, MAIP increases as the depth increase. In the sandstone formation, the same trend exhibits as that of the shale formation. MAIP of shale formation is higher than that of sandstone formation even the depth of shale formation is smaller than the depth of sandstone formation. The critical failure point lies at the top of sandstone formation. If shear failure happens in the lower sandstone formation, upper shale formation can provide properly sealing ability. 

along the tubing is in the MAIP window, the cement sheath of the well is in fair condition. When the tubing pressure exceeds the MAIP of weak cement, the cement sheath is exposed to high risk of failure. When the pressure is lower than the MAIP of strong cement, the cement sheath is free of mechanical failure.

Even weak cement presents better sealing abilities than that of strong cement; it does not mean the weak cement is the best choice. The main reason is that the porosity of weak cement is also higher than the strong cement. In carbon sequestration project, the cement sheath is exposed to $\mathrm{CO}_{2}$ corrosion. Cement sheath with higher porosity has more $\mathrm{CO}_{2}$ exposed areas than cement sheath with low porosity. It is high possibility that high porosity cement sheath would be corroded faster than low porosity cement sheath. The effective way is to design properly $\mathrm{CO}_{2}$ injection pressure to maintain the cement sheath integrity.

\section{Conclusion}

This paper provides an analytical solution to evaluate the cement sheath integrity. Mechanical properties of both cement sheath and formation are addressed in this model. Anisotropy stress state of formation is also considered.

Young's modulus of cement sheath is a major factor that affects the sealing ability of cement sheath, while Poisson's ratio and cohesion plays less important roles on the cement sheath sealing ability evaluation. Cement sheath set in the shale formation exhibits higher sealing ability than that in the sandstone formation. The performance of weak cement sheath is better than the strong cement sheath.

The concept of MAIP window is also proposed to evaluate the mechanical integrity of cement sheath. The critical failure point lies at the top of sandstone if shale formation is above it. Even weak cement gives higher MAIP; it is easier to be corroded than the strong cement. This is because the porosity of weak cement is higher than that of strong cement.

\section{Acknowledgment}

The work present in this paper was supported by the United States Department of Energy's National Energy Technology Laboratory (NETL), Federal Grant ID Number: DE FE0009284. Any opinions, findings and conclusions or recommendations expressed in this paper are those of the authors and do not necessarily reflect the views of the NETL.

\section{Nomenclature \\ $\sigma_{1}^{\infty}=$ maximum far-field principle stress, psi \\ $\sigma_{2}^{\infty}=$ minimum far-field principle stress, psi}




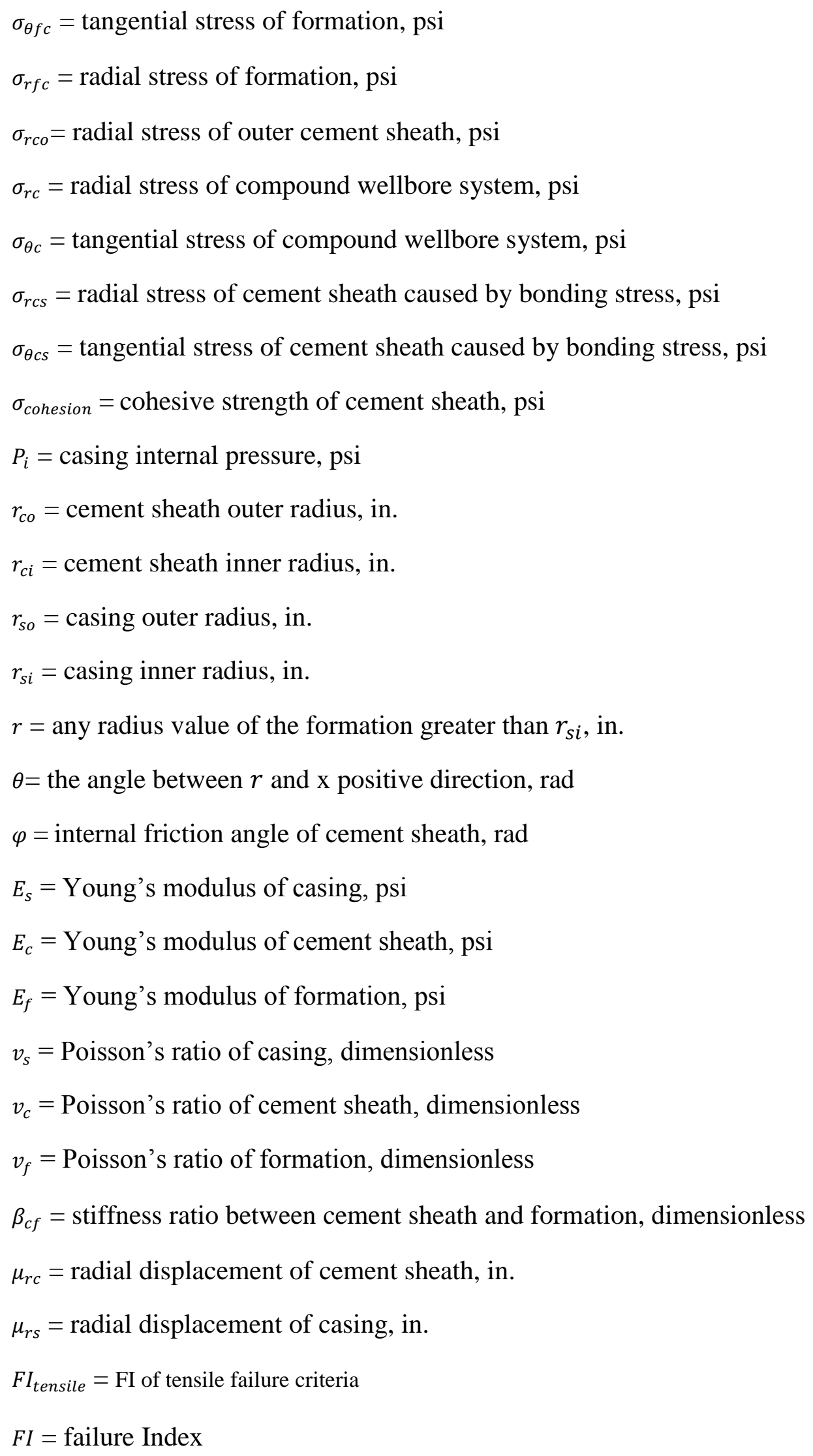


MAIP = Maximum allowable injection pressure

$\mathrm{ft}=$ feet

\section{SI Metric Conversion Factors}

$\mathrm{ft} \quad \mathrm{x} 3.048 * \mathrm{E}-01=\mathrm{m}$

in. $\mathrm{x} 2.54 * \mathrm{E}+00=\mathrm{cm}$

psi $\times 6.894757 \mathrm{E}+00=\mathrm{kPa}$

\section{Reference}

Bosma, M., Ravi, K. , Driel, W. and Schreppers, G.J., 1999, Design Approach to Sealant Selection for the Life of the Well, SPE Annual Technical Conference and Exhibition, Houston, Texas, SPE56536, October, 1999.

Boukhelifa, L., Moroni, N., James, S.G., Le Roy-Delage, S., Thiercelin, M.J., Lemaire, G. 2005, Evaluation of Cement Systems for Oil and Gas Well Zonal Isolation in a Full-Scale Annular Geometry, SPE Drilling \& Completion, pp44-53.

Bruckdorfer, R.A., 1986, Carbon Dioxide Corrosion in Oilwell Cements, SPE Annual Meetings, Rocky Mountain Region, Billing, MT, USA.

Deussen, A. and Guyod, H., 1937, Use of Temperature Measurement for Cementation Control and Correlations in Drill Holes, AAPG Bulletin, 21, No.6, pp789-805.

GIS Viewer, Railroad Commission of Texas, http://wwwgisp.rrc.state.tx.us/GISViewer2/

Goodwin, K.J. , Crook, R.J., 1992, Cement Sheath Stress Failure, SPE Drilling Engineering, SPE20453, pp291-296.

Haider, M.G., Sanjayan, J., Ranjith, P.G., 2012, Modeling of a Well-bore Composite Cylinder System for Cement Sheath Stress Analysis in Geological Sequestration of $\mathrm{CO}_{2}$.

Jaeger, J.C., Cook, N.G.W. and Zimmerman, R.W., 2007, Fundamentals of Rock Mechanics, fourth edition, Blackwell Publishing, ISBN 978-0-632-05759-7, pp228-230.

Kalil, I. A., McSpadden, A.R., 2012, Casing Burst Stresses in Particulate-Filled Annuli: Where is the Cement? , SPE 139766, SPE Drilling \& Completion, pp473-485.

Kutchko, B.G., Strazisar, B.R., Huerta, N., Lowry, G.V., Dzombak, D.A. and Thaulow, N. 2009, $\mathrm{CO}_{2}$ Reaction with Hydrated Class $\mathrm{H}$ Well Cement under Geologic Sequestration Conditions: Effects of Flyash Admixtures, Environmental Science \& Technology, pp 3947-3952, Vol. 43, No. 10. 

Prediction in a Carbon Sequestration Project Using Neural Networks, Journal of Sustainable Energy Engineering, Volume 2, Number 4, pp. 331-349(19).

Milestone, N.B., Bigley, C.H., Durant, A.T. and Sharp, M.D.W., 2012, Effects of $\mathrm{CO}_{2}$ on Geothermal Cements, GRC Transactions, pp 301-306, Vol. 36.

Mueller, D.T., GoBoncan, V. , Dillenbeck, R.L., Heinold, T., 2004, Characterizing CasingCement-Formation Interactions Under Stress Conditions: Impact on Long Term Zonal Isolation, SPE 90450, presented at the SPE Annual Technical Conference and Exhibition, Houston, TX., USA.

Phase change data for Carbon dioxide, National Institute of Standards and Technology, http://webbook.nist.gov/cgi/cbook.cgi?ID=C124389\&Units=SI\&Mask=4\#Thermo-Phase.

Saint-Marc, J., Garnier, A., Bois, A., 2008, Initial State of Stress: the Key to Achieving LongTerm Cement Sheath Integrity, SPE116651, presented at SPE annual technical conference and exhibition, Denver, CO. USA.

Shadravan, A., Schubert, J., Amani, M., Teodoriu, C., 2015, Using Fatigue-failure Envelope for Cement Sheath Integrity Evaluation. SPE168321, SPE Drilling \& Completion, pp68-75.

Shi, Y., Li, B., Guo, B., Guan, Z., Li, H., 2015, An Analytical Solution to Stress State of CasingCement Sheath-Formation System with the Consideration of Its Initial loaded State and Wellbore Temperature Variation, International Journal of Emerging Technology and Advanced Engineering, Volume 5, Issue 1, pp59-65.

Takase, K., Barhate, Y., Hashimoto, H., and Lunkad, S.F., 2010, Cement-sheath Wellbore Integrity for $\mathrm{CO}_{2}$ Injection and Storage Wells, SPE Oil and Gas India Conference and Exhibition, Mumbai, India.

Tarco, J.C. and Asghari, K., 2010, Experimental Study of Stability and Integrity of Cement in Wellbores Used for $\mathrm{CO}_{2}$ Storage, Journal of Canadian Petroleum Technology, pp 37-44, Vol. 9, No. 10.

Teodoriu, C., Ugwu, L., Schubert, J. , 2010, Estimation of Casing-Cement-Formation Interaction using a new Analytical Model, SPE 131335, presented at SPE Annual Conference and Exhibition, Barcelona, Spain.

Thiercelin, M.J., Dargaud, B., Baret, J.F. and Rodriquez, W.J., 1998, Cement Design Based on Cement Mechanical Response, SPE 52890, SPE Drilling \$ Completion, pp266-273, December, 1998.

Thomas, W.A., 1953, Hastings Field Brazoria and Galveston Counties, Texas. Huston Geological Society, 2007-Guidebooks, Field Trip Routes, Oil Fields, Geology, pp121-124. 
Yalcinkaya, T., Radonjic, M., Hughes, R.G. , Villson, C.S. and Ham, K., 2011, The Effect of $\mathrm{CO}_{2}$-Staurated Brine on the Conductivity of Wellbore-Cement Fractures, SPE Drilling \& Completion, pp 332-340. 